\title{
DIÁLOGO POSSÍVEL SOBRE LIBERDADE E POLÍTICA: Hannah Arendt e Rousseau
}

DIALOGUE POSSIBLE ON FREEDOM AND POLITICS: Hannah Arendt and Rousseau POSIBLE DIALOGO SOBRE LA LIBERTAD Y LA POLÍTICA: Hannah Arendt y
Rousseau

Maria Olilia Serra

Doutora em filosofia pela Universidade de São Paulo (USP). Professora do Departamento de Filosofia da UFMA.

oliliaserra@gmail.com

RESUMO: Apresenta-se a reflexão de Hannah Arendt sobre a compaixão no contexto da Revolução Francesa, com ênfase para a referência a Rousseau. Em sua obra Sobre a Revolução, a autora enfatiza que, a despeito de preconceitos, a liberdade sempre foi o objetivo das Revoluções. Nesse sentido, direciona sua reflexão para as Revoluções Modernas, principalmente para o papel desempenhado pela questão social. Ao examinar a Revolução Francesa, Arendt destaca que a opção dos homens da Revolução pela compaixão que foi elevada à categoria de virtude política, foi inspirada em Rousseau. Mas, para Arendt, é a amizade e não a compaixão que tem relevância política. PALAVRAS-CHAVE: Hannah Arendt. Rousseau. Liberdade. Política. Revolução.

ABSTRACT: It presents Hannah Arendt's reflection about compassion in the context of the French Revolution, with emphasis for the reference to Rousseau. In her work On revolution, the author emphasizes that, despite prejudices, freedom has always been the goal of the revolutions. Accordingly, she directs her reflection to the Modern Revolutions, mostly to the role played by social issues. When examining the French Revolution, Arendt emphasizes that the option of men of the revolution for the compassion that was elevated to the cathegory of political virtue, was inspired by Rousseau. But for Arendt, it is friendship not compassion that has political relevance.

KEYWORDS: Hannah Arendt. Rousseau. Freedom. Policy. Revolution.

RESUMEN: Presentamos la reflexión de Arendt sobre la compasión en el contexto de la Revolución Francesa, con énfasis para la referencia a Rousseau. En su obra Sobre la revolución, el autor subraya que, a pesar de los prejuicios, libertad siempre ha sido el objetivo de las revoluciones. En consecuencia, dirige su reflexión a las revoluciones modernas, sobre todo al papel desempeñado por las cuestiones sociales. Al examinar la Revolución francesa, Arendt enfatiza que la opción de los hombres de la revolución por la compasión que fue elevada a la categoría de virtud política, fue inspirada por Rousseau. Pero para Arendt, la amistad y la compasión no tiene relevancia política.

PALABRAS CLAVE: Hannah Arendt. Rousseau. Libertad . Política . Revolución. 


\title{
1 | INTRODUÇÃO
}

A pensadora Hannah Arendt (1906-1975) tem como foco de suas reflexões os acontecimentos políticos do século XX, o que evidencia o seu tema preferencial: a política com as suas questões conexas, mas, principalmente, a liberdade. Por isso, para a autora, "a liberdade é a razão de ser da política".

Em sua obra Sobre a Revolução, publicada em 1963, a autora examina as Revoluções Francesa e Americana, tendo como fio condutor a liberdade. Nesse sentido, enfatiza que o objetivo das Revoluções é a constituição da liberdade, ou seja, como a "fundação de um corpo político que garante um espaço onde a liberdade pode se manifestar." Entretanto, na contemporaneidade, a noção de liberdade foi colocada no centro do debate sobre a guerra e o uso justificável da violência. A autora lembra que é bem verdade que a relação entre início e violência é atestada nos inícios lendários da antiguidade bíblica e na antiguidade clássica: Caim matou Abel, Rômulo matou Remo. Tais atos, lendários ou não, percorreram os séculos com a força que o pensamento alcança nos "raros casos em que cria metáforas irresistíveis ou narrativas universalmente aplicáveis" (ARENDT, 2011, p. 46).

Em suas considerações sobre a Revolução Francesa, Arendt entende como um equívoco a utilização da revolução para solucionar a denominada "questão social", para aliviar a pobreza afastando-se da causa da liberdade. É nesse contexto que a autora faz referência a Rousseau:

Talvez seja um truísmo dizer que a libertação e a liberdade não se equivalem; que a libertação pode ser a condição da liberdade, mas de forma alguma conduz automaticamente a ela; que a noção de liberdade implícita na libertação só pode ser negativa e que, portanto, mesmo a intenção de libertar não é igual ao desejo de liberdade. (ARENDT, 2011, p. 57).

O presente artigo intenciona mostrar a crítica de Hannah Arendt à compaixão no contexto da Revolução Francesa, a partir do conceito rousseauniano, e aponta a amizade como a virtude política por excelência.

\section{2 | A CRÍTICA DA COMPAIXÃO}

No capítulo sobre o Significado da Revolução, Arendt observa que o antigo termo revolução não evoca a noção de novidade porque, pertencente ao vocabulário da astronomia, descreve um movimento recorrente e cíclico. Nas palavras da autora,

\begin{abstract}
A palavra 'revolução', originalmente, era um termo astronômico que ganhou importância nas ciências naturais graças a De Revolutionibus Orbium Coelestium, de Copérnico. Nesse uso científico, ela manteve seu significado latino exato, designando o movimento regular e necessário dos astros em suas órbitas, o qual, por estar sabidamente fora do alcance e sendo por isso irresistível, certamente não se caracterizava pela novidade nem pela violência [...]. A palavra indica com toda clareza um movimento cíclico e recorrente [...]. Nada podia estar mais distante do significado original da palavra 'revolução'" do que a ideia que possuía e obcecava todos os atores revolucionários, a saber, que eram agentes num processo que consistia no fim definitivo de uma ordem antiga e no nascimento de um mundo novo. (ARENDT, 2011, p. 72).
\end{abstract}

Tendo em vista o significado da Revolução, a autora volta a sua reflexão para as revoluções modernas. Para Arendt, não se pode negar, principalmente, o papel desempenhado pela questão social em todas as revoluções. Aristóteles já afirmava que o interesse ou "aquilo que é útil para 
DIÁLOGO POSSÍVEL | Maria Olilia Serra

uma pessoa, um grupo ou um povo, é e deve ser a norma suprema a reger os assuntos políticos" (ARENDT, 2011, p. 49), mas

a questão social começou a desempenhar um papel revolucionário somente quando os homens, na era moderna e não antes, começaram a duvidar de que a pobreza fosse inerente à condição humana, a duvidar de que a distinção entre a minoria que, à força, pela fraude ou pelas circunstâncias, havia conseguido se libertar dos grilhões da pobreza e as massas trabalhadoras miseráveis fosse eterna e imutável. (ARENDT, 2011, p. 49).

A questão social, cujo viés é a existência da pobreza, irrompe no palco da política, de acordo com Arendt (2011, p. 93), durante a Revolução Francesa:

A pobreza é mais do que a privação, é um estado de carência constante e miséria aguda cuja ignomínia consiste em sua força desumanizadora, a pobreza é sórdida porque coloca os homens sob o ditame absoluto de seus corpos, isto é, sob o ditame absoluto da necessidade que todos os homens conhecem pela mais íntima experiência e fora de qualquer especulação. Foi sob o império dessa necessidade que a multidão se precipitou para ajudar a Revolução Francesa, inspirou-a, levou-a em frente e acabou por conduzi-la à ruina, pois era a multidão dos pobres.

Arendt chama a atenção para o fato de que a liberdade, essência das Revoluções, da política, teve que se render à necessidade, ao processo vital em si. Nesse sentido, Robespierre declarou ser um bem comum tudo que fosse necessário para manter a vida. Ele sujeitava, assim, o governo revolucionário à necessidade. Principalmente, no contexto das Revoluções é a pobreza que desperta a Compaixão. Entretanto, cumpre destacar que os homens da Revolução Francesa tinham sido inspirados pelo ódio à tirania. Registra a autora:

Foi contra a tirania e a opressão, e não contra a exploração e a pobreza, que eles afirmaram os direitos do povo, cujo consentimento-segundo a antiguidade Romana, em cuja escola o espírito Revolucionário estudou e se formou- é necessário para dar legitimidade a todo poder. Visto que eles mesmos eram claramente destituídos de poder do ponto de vista político e, portanto, incluíam-se entre os oprimidos, sentiam-se parte do povo e não precisavam invocar qualquer solidariedade com ele. Se se tornaram porta-vozes do povo, não foi no sentido de que fizeram algo pelo povo, fosse por amor ou por desejo de obter poder sobre ele; falaram e agiram como seus representantes numa causa comum. (ARENDT, 2011, p. 110).

A compaixão teve um papel crucial nos sentimentos e nas reflexões dos homens que prepararam e atuaram durante a Revolução Francesa. Para Robespierre, líder dos jacobinos que assumiram o poder, "a única força que poderia e deve unir as diferentes classes da sociedade numa só nação era a compaixão dos que não sofriam por aqueles que eram malhereux, das classes superiores pelo povo simples" (ARENDT, 2011, p. 117).

De acordo com Arendt, a opção dos homens da Revolução pela compaixão tem inspiração em Rousseau. Para o genebrino,

a bondade do homem no estado de natureza se tornara um axioma porque a compaixão era considerada como 'a reação humana mais natural ao sofrimento do próximo e, portanto, seria o próprio fundamento de toda relação humana 'natural' autêntica'. Não que Rousseau, e aliás tampouco Robespierre, tivesse algum dia conhecido a bondade inata do homem natural fora da sociedade; eles deduziram sua existência a partir da corrupção da sociedade [...]. (ARENDT, 2011, p. 117). 


\section{DIÁLOGO POSSÍVEL | Maria Olilia Serra}

Ainda comentando Rousseau, Arendt registra que o autor evidencia, com toda a sua passionalidade, a capacidade de sofrimento do homem contra o egoísmo da sociedade, bem como contra a "solidão imperturbável da mente, entregue ao diálogo consigo mesmo". exercendo uma influência enorme sobre o espírito dos homens que fariam a Revolução pois, ressalta Arendt (2011, p. 119):

a magia da compaixão consistia em abrir o coração do sofredor aos sofrimentos alheios, estabelecendo e confirmando assim o laço 'natural' entre os homens, que apenas os ricos tinham perdido. Onde a paixão, a capacidade de sofrer com os outros, terminavam, aí começava o vício. O egoísmo era uma espécie de depravação natural. Se foi Rousseau quem introduziu a compaixão na teoria política, foi Robespierre quem a levou à praça pública com o vigor de sua grandiloquência Revolucionária.

A evidência da compaixão tem como pano de fundo o problema do bem e do mal com seu impacto sobre os destinos humanos, presente no espírito dos homens no exato momento em que afirmavam a dignidade sem recorrer à religião. Mas, para Arendt, a profundidade do problema não foi captada pelos homens desse tempo. Ao fazer referência ao problema do bem e do mal, ela ressalta que:

esse problema dificilmente poderia ser captado por quem confundia bondade com a 'repugnância inata do homem em ver o semelhante sofrer' (Rousseau) e por quem achava que o egoísmo e a hipocrisia eram o suprassumo da maldade [...]. A única experiência realmente válida, realmente convincente do amor ativo pela bondade como princípio inspirador de todas as ações que a humanidade ocidental teve ocasião de conhecer, isto é, sem levar em conta a figura de Jesus de Nazaré. (ARENDT, 2011, p. 119).

\section{Em mais uma referência a Rousseau, Hannah Arendt (2011, p. 127) enfatiza que:}

[...] é mais do que duvidoso que Rousseau tenha descoberto a compaixão ao partilhar o sofrimento alheio, e é mais do que provável que nisto... ele tenha se guiado por sua revolta contra a alta sociedade, especialmente contra sua flagrante indiferença do salão e a insensibilidade da razão que, diante do infortúnio de um outro dizem: morram à vontade, que estou a salvo.

Contudo, para a autora da Condição Humana, a compaixão é entendida como emoção e sentimento, o que não é exatamente isto para o filósofo Rousseau, que relaciona a piedade natural, ou melhor, a pitié, à consciência moral ${ }^{1}$, pois o sentimento jamais esteve na base da ação moral.

\footnotetext{
1 Conforme Salinas Fortes, "é quase impossível, na realidade, imaginar como atuaria no estado de natureza um 'sentimento' relativo como a comiseração, já que toda relação supõe necessariamente a passagem para o estado de sociedade. [...] O que importa é que Rousseau pretende que essa capacidade de sofrer no outro ou de se compadecer é na sua essência um impulso 'natural', ou seja, uma disposição que faz parte intrínseca da natureza humana, embora no estado de natureza ela goze de uma completa 'virtualidade'. [...] Ou, por outras palavras: ninguém se torna 'sensível' a não ser 'quando sua imaginação se anima e começa a transportá-lo para fora de si'. Ou ainda: podemos dizer que o que é natural ao homem é a capacidade de compaixão de que se podem encontrar seguros indícios até mesmo entre os animais. O desenvolvimento posterior e pleno da capacidade de identificação com o outro só se dá efetivamente com o desenvolvimento das 'luzes', da imaginação e das relações sociais; mas o que Rousseau pretende é que este desenvolvimento tenha um apoio na natureza, não sendo plenamente artificial. $A$ mor-de-si e pitié são paixões naturais e primitivas: eis aí uma 'evidência' indemonstrável a não ser indiretamente - por exemplo, quando se observa sua presença até mesmo no tirano que se comove, ao assistir a uma tragédia, com os sofrimentos do protagonista. Eis ai um verdadeiro axioma do sentimento ou da 'consciência moral' ou um 'postulado da razão prática' rousseauniana. É somente o paradoxo da descrição da natureza como um 'estado', ou as limitações da representação discursiva a nos exigirem o recurso à construção do modelo fictício de uma condição que talvez nunca tenha existido, que nos fazem confundir a caracterização do esquema de manifestação desse impulso com a determinação do seu estatuto ontológico." (SALINAS FORTES, 1997, p. 58-59).
} 
Além do que, a ética rousseauniana pressupõe a consciência moral, exercida sempre e necessariamente por intermédio da razão. Mas, conforme a interpretação da autora, o sentimento que corresponde "à paixão da compaixão" é a piedade. Segundo a análise de Arendt, a piedade pode ser a distorção da compaixão e a sua alternativa é a solidariedade. É por piedade que os homens são atraídos para "les hommes faibles", mas, por outro lado, é a solidariedade que estabelece uma comunidade de interesse com os oprimidos e explorados. Esse interesse comum seria "a grandeza do homem", "a honra da humanidade ou a dignidade humana". É digno de nota que a solidariedade é despertada pelo sofrimento mas não se guia por ele e abrange não só os fracos e os pobres como também os fortes e os ricos.

A piedade, ressalta Arendt, pode ter êxito onde a compaixão sempre falha, pois ela pode alcançar a multidão e, portanto, como a solidariedade, pode ingressar na praça pública. Mas o seu traço forte, digamos assim, é que sem o infortúnio ela não existiria e, por isso, tem existência no interesse dos infelizes, tanto quanto a sede de poder tem interesse na existência dos fracos.

A glorificação dos pobres e o elogio do sofrimento como fonte de virtude por parte de Robespierre, ressalta Arendt, eram sentimentais e bastante perigosas, pois se configuram como um simples pretexto para o seu desejo de poder. Tomada como virtude, a piedade mostrou que possui uma capacidade maior que a própria crueldade. Vide as palavras encontradas numa petição de uma das seções da Comuna de Paris que traduziu a linguagem da piedade: "por piedade, por amor à humanidade, sejam desumanos" (par pitié, par amour pour l'humanité, soyez inhumains!) (ARENDT, 2011, p. 128).

Mesmo que Robespierre tivesse sido motivado "pela paixão da compaixão, sua compaixão teria se tornado piedade ao ser trazida a campo aberto, onde não poderia mais direcioná-la para um sofrimento específico e concentrá-la em pessoas determinadas" (ARENDT, 2011, p. 128). Em Robespierre, a virtude transformou-se em um mal, em termos políticos, porque não aceitava limites. Inspirada na piedade, desde o seu começo essa virtude "pisoteou a justiça e atropelou as leis". Ao abrir os portões da esfera política aos pobres, a Revolução a transformou em uma esfera "social", que, de acordo com a compreensão de Arendt, pertencia à esfera doméstica. E as questões da esfera doméstica não podiam ser resolvidas através do processo de decisão e persuasão, haja vista que tais questões eram administrativas e da alçada de especialistas.

Para concluir a crítica da compaixão, ressaltamos que, se uma revolução tem como objetivo precípuo a fundação da liberdade, a Revolução Francesa, ao fazer a opção pelo sentimento, teve o seu curso desviado. Conforme Arendt (2011, p. 131):

\footnotetext{
O rumo da Revolução, quase desde o início, foi desviado desse curso de fundação pela imediaticidade do sofrimento; ele foi determinado pelas exigências de libertação não da tirania, e sim da necessidade, e foi movido pela ilimitada imensidão tanto da miséria do povo quanto da piedade inspirada por essa miséria. A ausência de legalidade do 'tudo é permitido' aqui brotava dos sentimentos do coração cujo, próprio caráter ilimitado contribuiu para desencadear um turbilhão de violência igualmente ilimitada.
}

Na verdade, o que Arendt tenta mostrar com sua reflexão é o papel desastroso da compaixão, da bondade, do coração ou da alma quando são expostos ao domínio público, pois ambos estão ligados ao domínio do privado, do íntimo, em que vale o preceito: "que a tua mão esquerda ignore o que faz a tua mão direita". 


\title{
3 | A POLÍTICA DA AMIZADE
}

No ensaio A humanidade em Tempos Sombrios: pensamentos sobre Lessing, em Homens em Tempos Sombrios, Arendt faz mais uma referência a Rousseau e à compaixão como uma repugnância inata ao sofrimento de um outro ser humano. Em sintonia com essa ideia, Lessing afirmou que a melhor pessoa é a mais compassiva, porém o caráter igualitário da compaixão possui um elemento perturbador, pois sentimos também "algo próximo da compaixão pelo malfeitor". Arendt (1991, p. 22) destaca que:

Isto não incomodava Rousseau. Conforme ao espírito da Revolução Francesa que se apoiou nas suas idéias, este via na fraternité a realização plena da humanidade. Lessing, em contrapartida, considerava ser a amizade - tão seletiva como a compaixão é igualitária - o fenômeno central, o único em que a verdadeira humanidade se pode evidenciar.

A amizade, registra Arendt, é relevante para a questão da humanidade e para a política. Os antigos consideravam os amigos indispensáveis à vida humana, pois uma vida sem amigos não era verdadeiramente digna de ser vivida. No mundo moderno, graças a Rousseau, a amizade é considerada apenas como fenômeno da intimidade, em que os amigos abrem o coração uns aos outros, alheados do mundo e das suas exigências. Esse alheamento é típico do indivíduo moderno que reflete a sua alienação em relação ao mundo e só se revela na "privacidade e intimidade dos encontros frente a frente". Em Aristóteles, a philia, a amizade entre os cidadãos, é um dos requisitos fundamentais para o bem estar da cidade, o que não significa apenas ausência de guerras civis e facções. Conforme Arendt (1991, p. 35-36):

\begin{abstract}
Mas para os gregos a essência da amizade consistia no diálogo. Afirmavam que só o intercâmbio constante da conversação podia unir os cidadãos na pólis. No diálogo manifestavam-se claramente a importância política da amizade e a humanidade que lhe é própria. Esta conversação (por oposição à conversa íntima em que os indivíduos falam sobre si próprios), por muito impregnada que possa estar do prazer na presença do amigo, diz respeito ao mundo comum, que se torna 'inumano', num sentido muito literal, a menos que seja objeto constante do diálogo dos seres humanos.
\end{abstract}

A amizade, afirma Arendt (1993, p. 98), no ensaio Filosofia e Política, "consiste, em grande parte, na verdade, nesse falar sobre algo que os amigos têm em comum". A amizade leva a igualação, mas isso não significa que os amigos se tornem os mesmos ou que sejam iguais entre si, mas que se tornem parceiros iguais em um mundo comum e que em conjunto formem uma comunidade. Então, o que a amizade alcança é a comunidade, cuja igualação traz em seu bojo a diferenciação sempre crescente dos cidadãos, inerente a uma vida agonística. Por isso, mais uma vez a autora lembra Aristóteles, que afirma ser a amizade e não a justiça o vínculo nas comunidades.

$\mathrm{Na}$ amizade, o elemento político reside no verdadeiro diálogo, no fato de que cada um dos amigos pode compreender a verdade inerente à opinião do outro. Conforme Arendt (1993, p. 99):

Mais do que o seu amigo como pessoa, um amigo compreende como e em que articulação específica o mundo comum aparece para o outro que, como pessoa, será sempre desigual ou diferente. Esse tipo de compreensão em que se vê o mundo (como se diz hoje um tanto trivialmente) do ponto de vista do outro - é o tipo de insight político por excelência.

A experiência do diálogo como elemento da política tem o seu ponto de partida na pólis. Nesta, a ênfase é dada ao discurso como persuasão e não apenas como elemento de resposta. "Ser político, viver em uma pólis, significava que tudo era decidido mediante palavras e persuasão, e não força e violência" (ARENDT, 2010, p. 31). 
O elemento essencial do âmbito da pólis é a liberdade que, ressalta Arendt, apesar da oposição dos filósofos a essa vida, "situa-se exclusivamente na esfera política". Desse modo, a pólis era o espaço dos "iguais", diferentemente do lar que era o centro da mais severa desigualdade. No domínio do lar não existia liberdade, pois o seu governante só podia ser considerado livre quando deixava o lar e ingressava no domínio político, lugar dos iguais. Arendt aponta que, no mundo grego, "ser livre significava ao mesmo tempo não estar sujeito às necessidades da vida nem ao comando de outro e também não comandar. Significava nem governar nem ser governado" (ARENDT, 2010, p. 38).

O cidadão da pólis participava da vida política porque, tendo superado as necessidades do mero viver, movia-se no que Aristóteles chamava de "vida boa", a mais nobre, e não se limitava ao processo biológico da vida. Sem a vitória sobre as necessidades da vida, nem a vida nem a "vida boa" é possível, mas a política jamais existe em função da vida (ARENDT, 2010, p. 45).

Concluindo a sua obra Sobre a Revolução, Arendt faz referência à peça Édipo em Colono, de Sófocles, com a seguinte passagem:

Sófocles nos revela pela boca de Teseu, o fundador lendário e por isso o porta-voz de Atenas, o que permitia ao comum dos mortais, jovens e velhos, suportar o fardo da vida: era a pólis, o espaço dos atos livres e das palavras vivas dos homens, capaz de conferir esplendor à vida. (ARENDT, 2011, p. 351).

A palavra é fundamental para a vida na pólis e para a política radicada na amizade. Mas a linguagem que se relaciona com o domínio político é a doxa. Esta significa não apenas opinião, mas também glória e fama e, como tal, relaciona-se à esfera pública em que qualquer um pode aparecer e mostrar quem é. Fazer valer sua própria opinião traduz-se em ser capaz de mostrar-se, ser visto e ouvido pelos outros. Os atenienses orgulhavam-se de conduzir seus assuntos políticos pela fala e sem o uso da violência, distinguindo-se dos bárbaros e, por isso, acreditavam que a arte mais alta e verdadeiramente política era a retórica, a arte da persuasão. Logo, persuadir, peitheim, era a forma especificamente política de falar.

Arendt iluminava suas reflexões sobre a política com a figura de Sócrates, pois para a autora, ele unifica duas paixões contraditórias: a de pensar e a de agir. Dedicou-se à atividade de pensar, mas sem a pretensão de converter os cidadãos da pólis a quaisquer crenças ou convicções. Para esse intento usava a maiêutica, a arte da obstetrícia, pois, sublinha a autora, "queria ajudar os outros a darem à luz o que eles próprios pensavam, a descobrirem a verdade em sua doxa" (ARENDT, 1993, p. 97). A autora destaca que, a partir da proposta de Sócrates, o papel do filósofo não é governar a cidade, mas ser o seu "moscardo"; não é dizer verdades filosóficas, mas tornar seus cidadãos verdadeiros. Ser um "moscardo" é saber ferroar os cidadãos que, sem as ferroadas, continuarão adormecidos e calmos pelo resto de suas vidas, a não ser que sejam despertados. Desse modo, a diferença com Platão é decisiva porque Sócrates não queria educar o cidadão, e sim estava interessado em aperfeiçoar-lhes as "doxai" que integravam a vida política. Assim, para Sócrates, a função política do filósofo era ajudar a estabelecer um mundo comum, construído sob a égide da amizade, uma vez que a política é fundada no principio da isonomia.

Ainda no contexto da reflexão sobre a política, em A Condição Humana, Arendt afirma, ao fazer referência ao amor que, por natureza, é extramundano e, por isso, é apolítico, anti-político, e talvez a mais poderosa das forças humanas anti-políticas. Então, para Arendt, o que o Amor é em sua esfera própria e estritamente delimitada, o Respeito é na esfera mais ampla dos negócios humanos. O Respeito é uma espécie de amizade sem intimidade ou proximidade, é uma consideração pela pessoa, nutrida a distância que o espaço do mundo coloca entre nós e que independe de qualidades que possamos admirar ou de realizações que possamos ter em alta conta. 
Em síntese, o amor não é uma categoria válida em política, como não são também a compaixão ou a piedade. Assim, afirma Arendt (1991, p. 36) "que a humanidade deva ser sóbria e fria em vez de sentimental; que a humanidade se manifeste não na fraternidade mas na amizade; que a amizade não seja íntima e pessoal, antes implique uma exigência política e mantenha a ligação ao mundo [...]."

\section{4 | CONSIDERAÇÕES FINAIS}

O presente artigo objetivou destacar um diálogo possível, a partir das referências ao filósofo Rousseau, na obra Sobre a Revolução, de Hannah Arendt, no que se refere a crítica da compaixão no contexto da Revolução Francesa. Percebemos, pelo exposto, que Hannah Arendt não considera a causa dos pobres como projeto revolucionário. Essa posição é objeto de críticas de estudiosos e pessoas engajadas preocupadas com a pobreza. Mas, por outro lado, ao criticar a compaixão, a autora quer alertar para os perigos da inserção de sentimentos e emoções na esfera política. Sentimentos, de um modo geral, têm o seu lugar no coração humano cujo acesso é vedado ao nosso conhecimento e, quando dão a aparecer diante dos outros, podem dissimular as verdadeiras intenções. Nesse sentido, Arendt (2011, p. 136-137) registra que:

O coração [...] mantém vivos seus recursos graças a uma luta constante que se desenrola em suas sombras e por causa de suas sombras. Quando dizemos que ninguém, exceto Deus, pode ver (e talvez suportar ver) um coração humano desnudado, o 'ninguém' inclui o próprio eu [...]. A verdade da âme déchirée de Rousseau, afora sua função na formação da volonté générale, é que o coração só começa a bater como deve quando se parte ou se dilacera num conflito [...].

Com relação a Rousseau e à questão da compaixão, que se traduz na piedade, é uma virtude natural que, de acordo com seus comentadores, é a base para a comunicação e a relação com o Outro e também para uma proposta de educação. Concluímos com a seguinte citação de Rousseau:

Só nos entregaremos a ela na medida em que ela estiver de acordo com a justiça, pois de todas as virtudes a justiça é a que mais concorre para o bem comum dos homens. É preciso, pela razão, por amor à nós, ter ainda mais piedade de nossa espécie do que do nosso próximo. (ROUSSEAU, 2004, p. 353). 
DIÁLOGO POSSÍVEL | Maria Olilia Serra

\section{Referências}

ARENDT, H. A condição humana. Tradução Roberto Raposo. 11. ed. Rio de Janeiro: Forense Universitária, 2010.

Da revolução. Tradução Fernando Dídimo Vieira. 2. ed. Brasília: UNB; São Paulo: Editora Ática, 1990.

Filosofia e política. In: A dignidade da política. Tradução Helena Martins e outros. Rio de Janeiro: Relume Dumará, 1993.

Homens em tempos sombrios. Tradução Ana Luisa Faria. Lisboa: Relógio D’água, 1991.

Sobre a revolução. Tradução Denise Bottman. São Paulo. Companhia das Letras, 2011.

DUARTE, A. O pensamento à sombra da ruptura: política e filosofia em Hannah Arendt. São Paulo: Paz e Terra, 2000.
GARCIA, C. B. Hannah Arendt: sobre as referências a Rousseau em On Revolution. In: CORREIA, A. (Coord.). Hannanh Arendt entre a filosofia e a política. Rio de Janeiro: Forense Universitária, 2002.

ORTEGA, F. Para uma política da amizade: Arendt, Derrida, Foucault. Rio de Janeiro: Relume Dumará, 2000.

ROUSSEAU, J.-J. Emílio, ou da educação. Tradução Roberto Leal Ferreira. 3. ed. São Paulo: Martins Fontes, 2004.

SALINAS FORTES, L. R. Paradoxo do espetáculo: política e poética em Rousseau. São Paulo: Discurso Editorial, 1997. 